\title{
The Difficult Diagnosis of Ischaemic Papillary Muscle Rupture \\ Case report from an urban emergency department
}

"Christian T. Braun, Meret E. Ricklin, Aristomenis K. Exadaktylos

$$
\text { تشخيص عسير لتمزق إفقاري في العضلة الحليمية }
$$

$$
\text { كريستيان براون، ميريت ريكلين، اريستومينس اكساداكوتلوس }
$$

\begin{abstract}
ABSTRAC T: We present a rare case of severe ischaemic papillary muscle rupture in a 67-year-old male patient who was admitted to the Emergency Department of the University Hospital Bern, Switzerland, in November 2013 with acute chest pain. On admission, the patient's blood pressure was $60 / 40 \mathrm{~mm} / \mathrm{Hg}$, his pulse was 110 beats per minute and his respiratory rate was 20 breaths per minute. An electrocardiogram was normal and focused assessment with sonography in trauma was negative. Transthoracic echocardiography showed possible thickening of the mitral valve leaflet with no indications of severe mitral insufficiency or wall motion abnormalities. Triple-ruleout computed tomography angiography revealed no pulmonary emboli or aortic dissection, although coronary atherosclerosis was present. Finally, severe insufficiency of the mitral valve with rupture of the papillary muscle, likely due to ischaemia, was observed via transoesophageal echocardiography. The patient underwent a successful surgical intervention and was discharged 10 days later in stable condition.
\end{abstract}

Keywords: Emergency Medicine; Shock; Myocardial Infarction; Papillary Muscles; Heart Rupture; Echocardiography; Case Report; Switzerland.

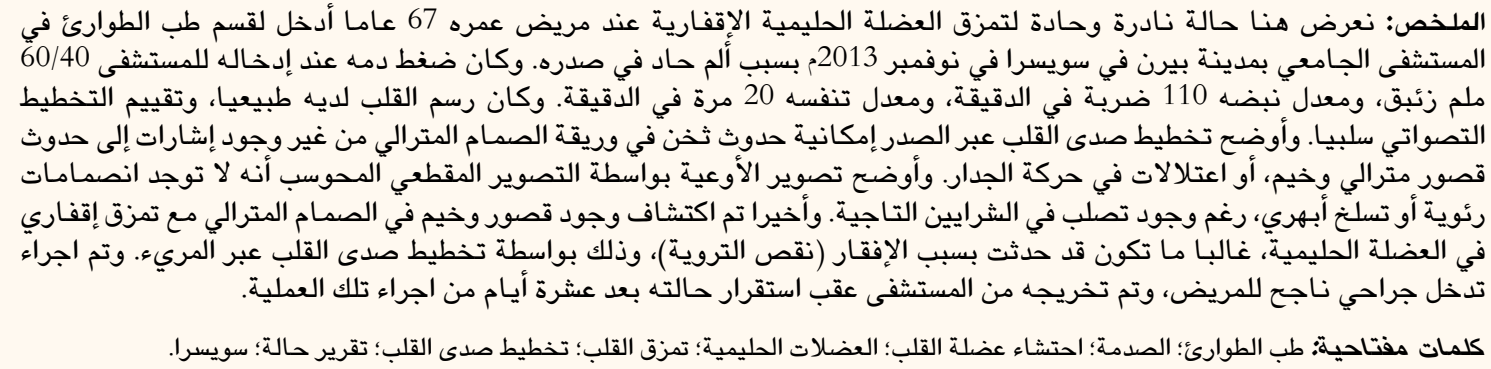

A LTHOUGH PATIENTS ADMITTED TO EMERGency departments often suffer from chest pain, the actual incidence of acute myocardial infarction is relatively low (approximately $2-3 \%)^{1,2}$ The rupture of a papillary muscle is a rare but generally fatal mechanical complication; it is found in $0.5-5 \%$ of patients with acute myocardial infarctions., ${ }^{3,4}$ Diagnosing an acute myocardial infarction becomes even more difficult if there is no evidence of acute ischaemia on an electrocardiogram and if echocardiography indicates no regional wall motion abnormalities. One of the current major challenges in emergency medicine is the rapid identification of these patients so as to treat them promptly with appropriate cardiac interventions. This report describes a rare case of severe ischaemic papillary muscle rupture diagnosed via transoesophageal echocardiography.

\section{Case Report}

A 67-year-old male was admitted to the Emergency Department of the University Hospital Bern in Switzerland in November 2013 with dyspnoea at rest and a one-hour history of chest pains radiating down both arms. When the ambulance arrived, his oxygen saturation in room air was $84 \%$. During transport to the hospital, the patient became hypotensive (blood pressure: 70/50 $\mathrm{mmHg}$ ). The patient's only known cardiovascular risk factor was a history of smoking cigarettes and he reported that he was not currently taking any regular medications. On arrival to the Emergency Department, the patient's blood pressure had reduced to $60 / 40 \mathrm{mmHg}$. He had a pulse of 110 beats per minute, a respiratory rate of 20 breaths per minute and his oxygen saturation was $96 \%$ after the 


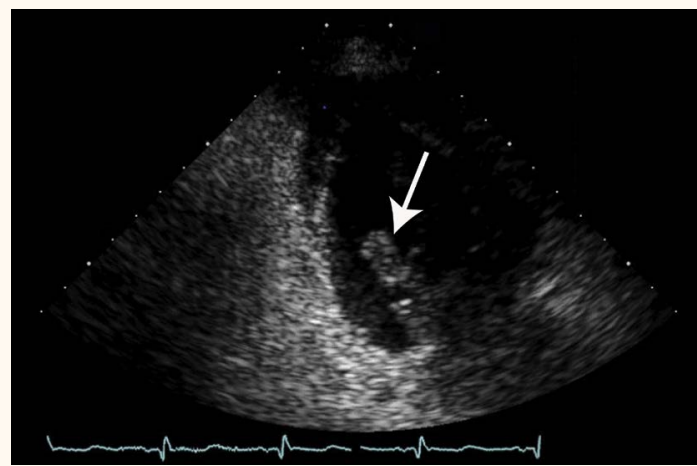

Figure 1: Transthoracic echocardiography showing a thickened posterolateral mitral leaflet (arrow) in a 67-year-old male patient with ischaemic papillary muscle rupture. Note the lack of wall motion abnormalities or pericardial effusion.

administration of $2 \mathrm{~L}$ of oxygen. His temperature was $36.8^{\circ} \mathrm{C}$ and consciousness was measured at level 14 of the Glasgow Coma Scale.

A physical examination of the patient on arrival indicated regular heart sounds with a systolic murmur; the heart sounds were heard most clearly above Erb's point. Auscultation of the lung, examination of the abdomen and a preliminary neurological examination were all normal. An electrocardiogram was normal with no evidence of acute ischaemia. Focused assessment with sonography in trauma was negative. Transthoracic echocardiography performed by cardiologists revealed a thickened mitral valve leaflet with mild mitral insufficiency and, most importantly, no wall motion abnormalities or pericardial effusion [Figure 1]. The left ventricular ejection fraction was estimated to be $65 \%$. Creatine kinase (1,319 U/L; normal value: $<190$ $\mathrm{U} / \mathrm{L})$, creatine phosphokinase-MB $(119.2 \mu \mathrm{g} / \mathrm{L}$; normal value: $<4.9 \mu \mathrm{g} / \mathrm{L})$ and high-sensitivity cardiac troponin $\mathrm{T}(2.150 \mu \mathrm{g} / \mathrm{L}$; normal value: $<0.014 \mu \mathrm{g} / \mathrm{L})$ levels were all substantially elevated. Although the patient was becoming increasingly haemodynamically unstable, the diagnosis remained unclear. Consequently, triplerule-out computed tomography was performed. No evidence of pulmonary emboli or aortic dissection was noted, although there were signs of general coronary atherosclerosis with plaques and without any luminal occlusion. The scan also revealed an infiltrate in the left upper lobe, perhaps due to aspiration pneumonia, with a small amount of left pleural effusion.

After diagnostic and laboratory testing, the patient was prescribed vasopressin before being intubated and receiving analgaesics. He was in a progressively unstable state and was re-evaluated by an interdisciplinary team, including intensive care physicians, cardiologists and emergency physicians. Although there were marked increases in heart enzymes, due to the lack of segmental wall motion abnormalities on transthoracic
Table 1: Comparison of transthoracic and transoesophageal echocardiographic findings for a 67-year-old male patient with ischaemic papillary muscle rupture

\begin{tabular}{|c|c|c|}
\hline Finding & TTE & TOE \\
\hline Left ventricular EF & Normal & Normal \\
\hline $\begin{array}{l}\text { Regional wall motion } \\
\text { abnormalities }\end{array}$ & None & None \\
\hline Pericardial effusion & None & None \\
\hline Papillary muscle rupture & $\begin{array}{l}\text { Thickened } \\
\text { mitral valve } \\
\text { leaflet }\end{array}$ & $\begin{array}{l}\text { Thickened } \\
\text { mitral valve } \\
\text { leaflet and } \\
\text { rupture of } \\
\text { the papillary } \\
\text { muscle }\end{array}$ \\
\hline $\begin{array}{l}\text { Mitral valve } \\
\text { regurgitation* }\end{array}$ & $\begin{array}{l}\text { Mild } \\
\text { insufficiency }{ }^{\dagger}\end{array}$ & $\begin{array}{l}\text { Severe } \\
\text { insufficiency }\end{array}$ \\
\hline Left atrium & No dilatation & $\begin{array}{l}\text { Dilatation } \\
\text { and severe } \\
\text { secondary } \\
\text { pulmonary } \\
\text { hypertension }\end{array}$ \\
\hline
\end{tabular}

$T T E=$ transthoracic echocardiography; $T O E=$ transoesophageal echocardiography; $E F=$ ejection fraction.

"Using colour Doppler imaging. ${ }^{\dagger}$ Small jet of mitral regurgitation. ${ }^{\ddagger}$ Large eccentric jet of mitral regurgitation.

echocardiography, a coronary angiogram was not immediately performed. The patient was transferred to the intensive care ward for further monitoring. While there, he rapidly developed cardiogenic shock and it was not possible to stabilise him. As a result, transoesophageal echocardiography was performed. This demonstrated severe mitral valve insufficiency with rupture of the papillary muscle, dilatation of the left atrium and severe secondary pulmonary hypertension. The left ventricular ejection fraction remained the same (65\%) and there were still no signs of any regional wall motion abnormalities [Table 1].

A coronary angiograph was subsequently carried out which showed that the papillary muscle rupture was caused by a distally occluded right coronary artery (RCA). As the patient remained unstable, cardiac surgery was performed. The mitral valve was replaced with a biological prosthesis and a coronary artery bypass graft was undertaken. The postoperative course was uneventful and the patient was discharged in a stable condition 10 days later.

\section{Discussion}

This report presents an unusual case of ischaemic papillary muscle rupture. Firstly, it is rare for cardiogenic shock to develop only a few hours after the onset of symptoms; the highest risk of shock is normally two to seven days after the myocardial infarction, when healing has begun. ${ }^{5}$ In this particular 
case, the short interval of time could potentially be explained by a silent ischaemic event occurring one or two days previously. Alternatively, the papillary muscle may have already been affected for some unrelated reason. ${ }^{6}$ Secondly, the lack of regional wall motion abnormalities is an uncommon finding, particularly in a hypotensive patient; the only possible explanation for this would be an acute papillary muscle rupture with severe acute mitral regurgitation. As in this case, the posteromedial papillary muscle is often affected during a myocardial infarction in the area perfused by the RCA; in comparison, the anterolateral papillary muscle has a dual blood supply and therefore very rarely exhibits ischaemic complications. ${ }^{1}$ Thirdly, it is rare for cases of papillary muscle rupture with severe mitral regurgitation to have an uncomplicated postoperative course, as observed with the current patient. This condition usually carries a high mortality rate; Schroeter et al. determined a 30-day postoperative mortality rate of $39.3 \%$, while another study reported rates of $4.2 \%$ and $25.0 \%$ for intraoperative and in-hospital mortality, respectively. ${ }^{7,8}$

Echocardiography is the imaging modality of choice for the non-invasive assessment of mechanical cardiac complications such as acute mitral regurgitation in the setting of a myocardial infarction. ${ }^{6}$ In these cases, the appearance of mitral regurgitation, often in relation to papillary muscle rupture, is an important sign of poor prognosis. ${ }^{9}$ Consequently, echocardiography plays an essential role in the early diagnosis, estimation of severity and determination of the pathomechanisms of ischaemic mitral regurgitation in patients with acute myocardial infarctions. ${ }^{9}$ Transoesphageal echocardiography has been well established as the initial diagnostic tool for identifying papillary muscle rupture, with a diagnostic sensitivity of 65-85\%. ${ }^{6}$ Due to the close proximity of the ultrasound transducer to the mitral apparatus, transoesophageal echocardiography is often used to improve reliability when diagnosing the cause of mitral regurgitation; it has been found to increase the diagnostic yield to approximately $95-100 \% .{ }^{10}$

Christ et al. described a case of partial papillary muscle rupture diagnosed solely by transoesophageal echocardiography; previous transthoracic echocardiographs had shown no pathologies or only posterior mitral leaflet prolapse. ${ }^{3}$ Similar experiences have been reported for patients with acute septal ruptures in the acute stage of a myocardial infarction. Maillier et al. found that only eight out of 15 septal ruptures could be visualised directly by conventional transthoracic echocardiography; in contrast, transoesophageal echocardiography successfully diagnosed 14 of the same patients..$^{10}$ However, Monin et al. found that only $5 \%$ of patients required transoesophageal echocardiography to adequately quantify the severity of mitral insufficiency. ${ }^{11}$ Transthoracic echocardiography is therefore an appropriate first-line imaging modality and transoesophageal echocardiography should be reserved for patients with poor-quality transthoracic images or those with continued deterioration and an unclear diagnosis.

\section{Conclusion}

Corresponding with previous findings in the literature, the current case report supports the view that transoesophageal echocardiography is a valuable tool to confirm the diagnosis of ischaemic papillary muscle rupture. In these cases, several diagnostic measures may often be needed. As such, the utilisation of transoesophageal, rather than transthoracic, echocardiography may lead to a life-saving diagnosis for patients who are cardiovascularly unstable.

\section{References}

1. Cherian PS, Clarke AJ, Burstow DJ. Unusual case of acute posteromedial papillary muscle rupture after acute anterior myocardial infarction. Heart Lung Circ 2014; 23:e16-19. doi: 10.1016/j.hlc.2013.07.005.

2. BayleyMD,SchwartzJS, ShoferFS, WeinerM,SitesFD, Traber KB, et al. The financial burden of emergency department congestion and hospital crowding for chest pain patients awaiting admission. Ann Emerg Med 2005; 45:110-17. doi: 10.1016/j. annemergmed.2004.09.010

3. Christ G, Siostrzonek P, Maurer G, Baumgartner H. Partial papillary muscle rupture complicating acute myocardial infarction: Diagnosis by multiplane transoesophageal echocardiography. Eur Heart J 1995; 16:1736-8.

4. Wei JY, Hutchins GM, Bulkley BH. Papillary muscle rupture in fatal acute myocardial infarction: A potentially treatable form of cardiogenic shock. Ann Intern Med 1979; 90:149-52. doi: 10.7326/0003-4819-90-2-149.

5. Thompson CR, Buller CE, Sleeper LA, Antonelli TA, Webb JG, Jaber WA, et al. Cardiogenic shock due to acute severe mitral regurgitation complicating acute myocardial infarction: A report from the SHOCK Trial Registry - Should we use emergently revascularize occluded coronaries in cardiogenic shock? J Am Coll Cardiol 2000; 36:1104-9.

6. Czarnecki A, Thakrar A, Fang T, Lytwyn M, Ahmadie R, PascoeE, et al. Acute severe mitral regurgitation: Consideration of papillary muscle architecture. Cardiovasc Ultrasound 2008; 18:6:5. doi: 10.1186/1476-7120-6-5.

7. Schroeter T, Lehmann S, Misfeld M, Borger M, Subramanian S, Mohr FW, et al. Clinical outcome after mitral valve surgery due to ischemic papillary muscle rupture. Ann Thorac Surg 2013; 95:820-4. doi: 10.1016/j.athoracsur.2012.10.050.

8. Bouma W, Wijdh-den Hamer IJ, KoeneBM,Kuijpers M, NatourE, Erasmus ME, et al. Predictors of in-hospital mortality after mitral valve surgery for post-myocardial infarction papillary muscle rupture. J Cardiothorac Surg 2014; 9:171 doi: 10.1186/ s13019-014-0171-z. 
9. Petris AO, Iliescu D, Alexandrescu DM, Costache II. Ischemic mitral regurgitation in patients with acute myocardial infarction. Rev Med Chir Soc Med Nat Iasi 2014; 118:618-23.

10. Maillier B, Metz D, Nazeyrollas P, Maes D, Chapoutot L, Jennesseaux C, et al. [Value of transesophageal echocardiography in post-infarction septal ruptures.] Arch Mal Coeur Vaiss 1996; 89:695-702.
11. Monin JL, Dehant P, Roiron C, Monchi M, Tabet JY, Clerc P, et al. Functional assessment of mitral regurgitation by transthoracic echocardiography using standardized imaging planes: Diagnostic accuracy and outcome implications. J Am Coll Cardiol 2005; 46:302-9. doi: 10.1016/j.jacc.2005.03.064. 